\title{
A Novel CD48-Based Analysis of Sepsis-Induced Mouse Myeloid-Derived Suppressor Cell Compartments
}

\author{
Bei Jia, ${ }^{1,2}$ Chenchen Zhao,, ${ }^{1,2}$ Guoli Li, ${ }^{1,2}$ Yaxian Kong, ${ }^{1,2}$ Yaluan Ma, \\ Qiuping Wang, ${ }^{4}$ Beibei Wang, ${ }^{1,2}$ and Hui Zeng ${ }^{1,2}$ \\ ${ }^{1}$ Institute of Infectious Diseases, Beijing Ditan Hospital, Capital Medical University, Beijing 100015, China
${ }^{2}$ Beijing Key Laboratory of Emerging Infectious Diseases, Beijing 100015, China
${ }^{3}$ Lab for Molecular Biology, Institute of Basic Theory on Chinese Medicine, China Academy of Chinese Medical Sciences, Beijing, China
${ }^{4}$ Clinical Laboratory, Beijing Tongren Hospital, Capital Medical University, Beijing 100730, China
}

Correspondence should be addressed to Beibei Wang; beibeiwang@ccmu.edu.cn and Hui Zeng; zenghui@ccmu.edu.cn

Received 22 September 2016; Accepted 10 January 2017; Published 26 February 2017

Academic Editor: Pham My-Chan Dang

Copyright (C) 2017 Bei Jia et al. This is an open access article distributed under the Creative Commons Attribution License, which permits unrestricted use, distribution, and reproduction in any medium, provided the original work is properly cited.

\begin{abstract}
Myeloid-derived suppressor cells (MDSCs) are a heterogeneous subset of cells that expands dramatically in many disease states and can suppress T-cell responses. MDSCs mainly include monocytic and granulocytic subpopulations that can be distinguished in mice by the expression of Ly6G and Ly6C cell surface markers. This identification system has been validated in experimental tumor models, but not in models of inflammation-associated conditions such as sepsis. We challenged growth factor independent 1 transcription repressor green fluorescent protein (Gfil:GFP) knock-in reporter mice with cecal ligation and puncture surgery and found that $\mathrm{CD}_{11 b^{+}} \mathrm{Ly}_{6 \mathrm{G}^{\mathrm{low}}} \mathrm{Ly} 6 \mathrm{C}^{\text {high }}$ MDSCs in this sepsis model comprised both monocytic and granulocytic MDSCs. The evidence that conventional Ly6G/Ly6C marker analysis may not be suited to study of inflammation-induced MDSCs led to the development of a novel strategy of distinguishing granulocytic MDSCs from monocytic MDSCs in septic mice by expression of CD48. Application of this novel model should help achieve a more accurate understanding of the inflammation-induced MDSC activity.
\end{abstract}

\section{Introduction}

Myeloid-derived suppressor cells (MDSCs) are a heterogeneous subset of immune system cells capable of suppressing T-cell responses by upregulating the expression of arginase- 1 (Arg-1), inducible nitric oxide synthetase (iNOS/NOS2), and reactive oxygen or nitrogen species [1-3]. In mice, MDSCs are firstly defined as $\mathrm{CD} 11 \mathrm{~b}$ positive and granulocyte antigen-

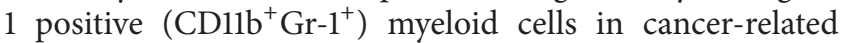
inflammation [4]. Since anti-Gr-1 antibody RB6-8C5 reacts with both lymphocyte antigens 6G and 6C (Ly6G and Ly6C) [5] and monocytes express Ly6C but not Ly6G, MDSCs are further distinguished as monocytic MDSCs (M-MDSCs,

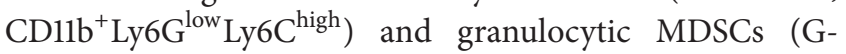
MDSCs, CD11b $\left.{ }^{+} \mathrm{Ly}_{6 \mathrm{G}^{\text {high }}} \mathrm{Ly} 6 \mathrm{C}^{\mathrm{low}}\right)$ in experimental murine models [6-8].

MDSC expansion occurs in a number of pathological conditions, including malignancies [9], acute or chronic inflammation [10, 11], trauma [12], autoimmune diseases [13, 14], and organ transplantation [15]. Unfortunately, Ly6G and Ly6C expression by myeloid cells appears to be variable. It has been reported that expression of Ly6C is influenced by inflammatory stimuli, such as interferon- $\gamma$ and tumor necrosis factor (TNF- $\alpha$ ) [16-18]. Ly6G expression by cells with a mononuclear morphology has also been demonstrated during virus infection [19]. Sepsis can trigger production of many inflammatory cytokines along with strong stimulation of myelopoiesis in bone marrow and spleen. It is not clear whether the conventional interpretation of CD11b and Ly6G/Ly6C expression is suitable for distinguishing monocytic and granulocytic MDSCs in septic mice.

Growth factor independence 1 (Gfil) is a nuclear zincfinger protein that regulates the survival, proliferation, and differentiation of hematopoietic cells [20-22]. We previously reported that it was expressed in granulocytes and not in monocytes in the bone marrow [23-25]. We generated 
Gfil:green fluorescent protein (Gfil:GFP) knock-in reporter mice and used GFP expression to identify Gfil expression in granulocytes and monocytes in the mice under physiological conditions [26]. Gene expression array analysis revealed that expression of CD48, a glypiated-linked protein in the signaling lymphocyte activation molecule family, was inversely correlated with Gfil expression. CD48 was strongly expressed on monocytes and weakly expressed on granulocytes in healthy Gfil:GFP mice [23].

In this study, we challenged Gfil:GFP knock-in reporter mice by cecal ligation and puncture (CLP) surgery and found that the population of $\mathrm{CD} 11 \mathrm{~b}^{+} \mathrm{Ly} 6 \mathrm{G}^{\mathrm{low}} \mathrm{Ly} 6 \mathrm{C}^{\text {high }}$ cells in this sepsis model were heterogeneous and consisted of both monocytic and granulocytic MDSCs and that CD48 can distinguish monocytic and granulocytic MDSCs during infection.

\section{Materials and Methods}

2.1. Mice. Gfil:GFP knock-in mice that were generated as described before [26] were kindly provided by Professor Tarik Möröy (Institut de Recherches Cliniques de Montréal, Canada). Male C57/BL6J specific-pathogen-free (SPF) mice of 6-8 weeks of age and weighing $18-20 \mathrm{~g}$ were purchased from the Institute of Laboratory Animal Science, Chinese Academy of Medical Science (Beijing, China). The mice were housed in groups of five with SPF soft wood shavings and ad libitum access to double-distilled water and commercial SPF pelleted food (GB14924.3-2010, HFK Bioscience, Beijing, China). All procedures performed on animals were approved by the Animal Care Research Ethics Committee of the Capital Medical University, Beijing, China.

2.2. Mouse Sepsis Model. Sepsis was induced by CLP or intraperitoneal injection of LPS. For CLP, Gfil:GFP knockin mice were anesthetized by intraperitoneal injection of ketamine $100 \mathrm{mg} / \mathrm{kg}$ and xylazine, $0.1 \mathrm{ml} / 10 \mathrm{~g}$. Midline laparotomy was performed after skin disinfection with iodine tincture (2\%). The cecum was divided approximately in half by a ligation distal to the ileocecal valve and was punctured once with an 18-gauge needle. The abdominal wall and skin were then sutured in layers with $4-0$ silk, and $1 \mathrm{ml}$ normal saline was injected subcutaneously for fluid resuscitation. This procedure induced sepsis with $\sim 60 \%$ mortality over 13 days. To induce acute sepsis, Gfil:GFP knock-in mice were given a single intraperitoneal injection of Escherichia coli pure LPS (Sigma-Aldrich, St. Louis, MO, USA) $10 \mathrm{mg} / \mathrm{kg}$ body weight.

2.3. Cell Preparation. Mice were sacrificed at 1,7 , and 12 days after CLP surgery or 3 hours after LPS injection. Blood, bone marrow, and spleen samples were collected aseptically from mice under deep anesthesia for subsequent experiments. Approximately $1 \mathrm{ml}$ blood was collected into ethylenediaminetetraacetic acid (EDTA) coated tubes via retrobulbar vein puncture. Bone marrow cells were flushed from the femurs and tibias with phosphate buffered saline (PBS, Gibco, Thermo Fisher Scientific, Waltham, MA, USA) after bilateral hind limb dissection. The spleen was removed, minced with scissors, and ground using a $70 \mu \mathrm{m}$ cell strainer (BD Falcon,
Bedford, MA, USA) under aseptic conditions. Erythrocytes were lysed with 1x Pharm Lyse solution (BD Biosciences, Sparks, MD, USA), and single spleen-cell suspensions were prepared by multiple pipetting and filtering through a $70 \mu \mathrm{m}$ nylon filter.

2.4. Flow Cytometry Analysis. Cells were labeled with antiCD11b conjugated to PerCP-Cy5.5, anti-Gr-1 conjugated to phycoerythrin (PE, BD Biosciences, Franklin Lakes, NJ, USA), anti-Ly6C and anti-CD48 conjugated to allophycocyanin (APC, Affymetrix, eBioscience, Santa Clara, CA, USA), and anti-Ly6G conjugated to PE (BioLegend, San Diego, CA, USA). An isotype control antibody was used in each staining procedure. Single cell suspensions were prepared from bone marrow, blood, and spleen of Gfil:GFP knock-in naïve controls, LPS-treated mice, and CLP mice. Cells were stained for 15 minutes at $4^{\circ} \mathrm{C}$ with primary antibodies in staining buffer (PBS with $2 \mathrm{mM}$ EDTA and $0.5 \%$ BSA v/w). Flow cytometry assays were performed using a FACS-Calibur and Aria II flow cytometer (BD Biosciences, Franklin Lakes, NJ, USA). About 100,000 cells were analyzed with FlowJo 10.0 software (FlowJo, LLC., Ashland, OR, USA).

2.5. Cell Sorting. Cell sorting was performed with an Aria II flow cytometer with $>95 \%$ purity. Bone marrow, spleen, and blood cells from Gfil:GFP knock-in mice were stained with the anti-CD11b, CD48 and Gr-1 antibodies as described

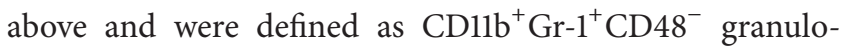

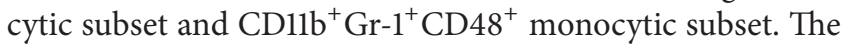
anti-CD11b, anti-Ly6G, and anti-Ly6C antibodies were used to sort $\mathrm{CD}_{11 b^{+}} \mathrm{Ly}_{6 \mathrm{G}^{\text {high }}} \mathrm{Ly} 6 \mathrm{C}^{\text {low }}$ granulocytic subset and $\mathrm{CD}_{11 b^{+}}$Ly6G $^{\text {low }}$ Ly6C ${ }^{\text {high }}$ monocytic subset. Sorted cells were washed and resuspended in sterile PBS. For $\mathrm{CD}^{+} \mathrm{T}$ cells sorting, cells were harvested from the spleen of C57/BL6J wild-type mice, and $\mathrm{CD} 4^{+} \mathrm{T}$ cells were purified by negative selection using a CD $4^{+}$T-Cell Isolation Kit II for magnetically assisted cell sorting (Miltenyi Biotec, Auburn, CA, USA) following the manufacturer's instructions.

2.6. Wright-Giemsa Staining and Cytological Analysis. Thinlayer preparations of suspensions containing $5 \times 10^{4}$ cells in $300 \mu \mathrm{l}$ PBS were made at $500 \mathrm{rpm}$ for 5 minutes using a cytospin-4 cytocentrifuge (Thermo Fisher). Cells were stained with a Wright-Giemsa kit (BASO, Wuhan, China) following the manufacturer's instructions. Briefly, cells were stained with buffer A for 1 minute and then buffer B for 10 minutes. After fixation and staining, slides were gently rinsed in tap water for 60 seconds and air-dried. A hematopathologist blinded to the study protocol conducted an independent analysis of the slides.

2.7. Cell Culture and Treatment. Following sorting, MDSC subgroups were cultured in RPMI 1640 medium supplemented with 10\% FBS (R10, Gibco, Thermo Fisher Scientific). For in vitro LPS stimulation, $1 \times 10^{6}$ cells were cultured in R10 with $100 \mathrm{ng} / \mathrm{ml}$ LPS for 3 hours and then assayed by flow cytometry. 
2.8. T-Cell Proliferation Assay. Purified CD $4^{+}$T lymphocytes from naïve mouse spleens were labeled with $1 \mathrm{mM}$ carboxyfluorescein N-hydroxysuccinimidyl ester (CFSE; Invitrogen, Portland, OR, USA). Cultures of $1 \times 10^{5}$ labeled $\mathrm{CD}^{+} \mathrm{T}$ cells and unlabeled G-MDSC or M-MDSC cells with $\mathrm{MDSC} / \mathrm{T}$ ratios of $1 / 4,1 / 2,1 / 1$, and $2 / 1$ were cultured in $\mathrm{R} 10$ in anti-CD3e $(5 \mu \mathrm{g} / \mathrm{ml}$; functional grade, clone $145-$ 2C11; eBioscience, Santa Clara, CA, USA) coated plates in the presence of soluble anti-CD28 $(5 \mu \mathrm{g} / \mathrm{ml}$; functional grade, clone 37.51; eBioscience). After 60 hours, cells were collected and stained with APC-conjugated anti-CD4 antibody and 7aminoactinomycin D (7-AAD, eBioscience). Proliferation of CFSE-labeled cells was assayed by flow cytometry.

2.9. Quantitative Real-Time PCR. Total RNA was extracted from sorted bone marrow and spleen MDSC subsets using TRIZOL reagent (Ambion, Thermo Fisher Scientific, Waltham, MA, USA). Approximately 20 ng RNA was transcribed into cDNA with a high capacity cDNA Reverse Transcription Kit (Applied Biosystems, Thermo Fisher Scientific, Foster City, CA, USA) following the manufacturer's protocol. Taqman master mix and probes for Arg-1 (Mm00475988_m1), Nos2 (Mn00440502_m1), and Gapdh (Mm03302249_g1) were purchased from Applied Biosystems. We used ABI Prism 7500 Sequence Detection System (Applied Biosystems, Foster City, CA, USA) to assay gene expression. Real-time PCRs were performed in triplicate for each sample, and averaged $\mathrm{C}_{t}$ values were used for calculations. Relative expression of Arg-1 and NOS2 mRNA was normalized to the bone marrow derived granulocytes from naïve mice.

2.10. Statistical Analysis. Results were reported as means \pm SEM, and between-group differences were analyzed with unpaired-sample student $t$-tests. The significance of withingroup differences was tested by analysis of variance. $P<0.05$ was considered significant. GraphPad Prism 6.0c (La Jolla, CA, USA) was used for statistical analysis and for graphing data.

\section{Results}

3.1. Ly6G and Ly6C Expression in MDSC Subsets of Septic Mice. We assayed Ly6G and Ly6C expression in different MDSC subsets obtained from Gfil:GFP knock-in mice with sepsis following CLP challenge. $\mathrm{CD}_{11 b^{+}}$myeloid cell populations included Ly6 $\mathrm{G}^{\text {high }} \mathrm{Ly}_{6} \mathrm{C}^{\text {low }}$ and Ly6 $6 \mathrm{G}^{\text {low }} \mathrm{Ly} 6 \mathrm{C}^{\text {high }}$ subpopulations by day 7 after CLP (Figure 1(a)). We sorted Ly6 $\mathrm{G}^{\text {high }}{ }^{\mathrm{Ly}} 6 \mathrm{C}^{\text {low }}$ and Ly6 $\mathrm{G}^{\text {low }} \mathrm{Ly} 6 \mathrm{C}^{\text {high }}$ cells from both naïve and CLP $7 \mathrm{~d}$ mice for Wright-Giemsa staining. Consistent with previous studies, the Ly6G ${ }^{\text {high }}$ Ly6 $6 C^{\text {low }}$ myeloid cells of naïve mice had typical granulocytic morphology with ring-shaped or segmented nuclei, and the Ly6 $\mathrm{G}^{\text {low }} \mathrm{Ly} 6 \mathrm{C}^{\text {high }}$ myeloid cells had typical monocytic morphology (Figures 1(b) and $1(\mathrm{c}))$. The Ly6 $6 \mathrm{G}^{\text {high }} \mathrm{Ly} 6 \mathrm{C}^{\text {low }}$ myeloid cells of CLP mice were a homogeneous granulocyte population. The significant finding was that the Ly $6 \mathrm{G}^{\text {low }} \mathrm{Ly} 6 \mathrm{C}^{\text {high }}$ myeloid cells of CLP mice included populations with both granulocytic and monocytic morphology (Figures 1(b) and 1(c)).
The GFP expression of $\mathrm{Ly} 6 \mathrm{G}^{\text {high }} \mathrm{Ly} 6 \mathrm{C}^{\text {low }}$ and Ly6G ${ }^{\text {low }}$ Ly6C $\mathrm{C}^{\text {high }}$ myeloid cells confirmed the cell sorting and Wright-Giemsa staining results. More than $99.5 \%$ of the Ly6 $\mathrm{G}^{\text {high }}$ Ly6C ${ }^{\text {low }}$ cells from naïve mice were $\mathrm{GFP}^{+}$, whereas the Ly6G ${ }^{\text {low }}$ Ly $6 \mathrm{C}^{\text {high }}$ cells were $\mathrm{GFP}^{-/ \text {low }}$, which indicated that they were granulocytes and monocytes, respectively (data not shown). Similar to $\mathrm{Ly} 6 \mathrm{G}^{\text {high }} \mathrm{Ly} 6 \mathrm{C}^{\text {low }}$ cells of naive mice, the Ly6 $6 \mathrm{G}^{\text {high }} \mathrm{Ly} 6 \mathrm{C}^{\text {low }}$ cells of day 7 CLP mice were $\mathrm{GFP}^{+}$(Figure $1(\mathrm{~d})$ ). In line with the morphologic data, $\mathrm{CD}_{11 b^{+}} \mathrm{Ly}_{6 \mathrm{G}}{ }^{\text {low }} \mathrm{Ly} 6 \mathrm{C}^{\text {high }}$ cells included both $\mathrm{GFP}^{+}$and $\mathrm{GFP}^{-}$ cells. The percentages of $\mathrm{GFP}^{-}$cells were $68.36 \pm 3.306 \%$ in bone marrow, $64.47 \pm 2.563 \%$ in spleen, and $95.4 \pm 1.453 \%$ in peripheral blood (Figures $1(\mathrm{~d})$ and $1(\mathrm{e})$ ). The results thus showed that $\mathrm{CD}_{11 b^{+}}{\text {Ly } 6 G^{\text {low }}}^{2}$ Ly $6 \mathrm{C}^{\text {high }}$ cells of CLP mice included both granulocytes and monocytes.

The influence of inflammation on the expression of Ly6C and Ly6G by granulocytic MDSC was evaluated in CD11b ${ }^{+}{\text {Ly } 6 G^{\text {low }}}^{\text {Ly6C }}{ }^{\text {high }}$ cells following sorting and stimulation by lipopolysaccharide (LPS, $100 \mathrm{ng} / \mathrm{ml}$ ) in vitro for 3 hours. We did not observe the emergence of the Ly6G ${ }^{\text {low }}$ Ly6C $C^{\text {high }}$ cells during culture (Figure 2(a)), which implies that short-term inflammatory stimulation did not influence the expression of Ly6C and Ly6G by the granulocytes. We also investigated the dynamic changes in the purity of Ly6 $6 \mathrm{G}^{\text {high }}$ Ly6C ${ }^{\text {low }}$ and Ly6G ${ }^{\text {low }}$ Ly6 $6 \mathrm{C}^{\text {high }}$ myeloid cells at different stage of sepsis. As shown in Figures 2(b) and 2(c), naïve mice and LPS-treated mice had comparable proportions of Gfil:GFP ${ }^{+}$granulocytes within the bone marrow Ly6G ${ }^{\text {low }}$ Ly6C $^{\text {high }}$ population $(3.654 \pm 0.948 \%$ versus $2.603 \pm$ $0.376 \%, P=0.2563)$. However, the percentage of Gfil:GFP ${ }^{+}$ in the Ly6G ${ }^{\text {low }}$ Ly $6 C^{\text {high }}$ subpopulation significantly increased from day 1 after CLP, peaked on day 7 (31.64 $\pm 3.306 \%, P<$ $0.0001)$, and then gradually decreased to about $12 \%$ on day $12(P<0.0001)$. The same dynamic pattern was confirmed in the spleen cells of septic mice. Thus, Ly6G/Ly6C expression is not suitable for distinguishing granulocytes and monocytes in septic mice.

3.2. CD48 Labeling Distinguished Granulocytes from Monocytes in Septic Mice. Although granulocytes and monocytes can be distinguished in Gfil:GFP knock-in mice in this mouse sepsis model, it would be more helpful to be able to distinguish them in wild-type mice. We thus used CD48 staining to assay the MDSC subsets in our sepsis model (Figure 3(a)). Fluorescence-activated cell sorting (FACS) analysis showed that, on day 7 after CLP, more

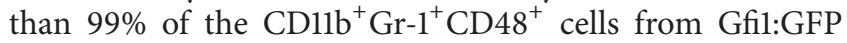

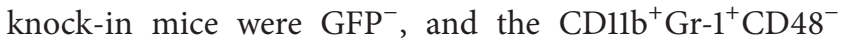
cells were $\mathrm{GFP}^{+}$(Figures 3(b) and 3(c)). Cell morphology analysis also confirmed that these two populations were monocytes and granulocytes, respectively (Figures 3(d) and $3(\mathrm{e})$ ). Furthermore, we investigated CD48 expressions on

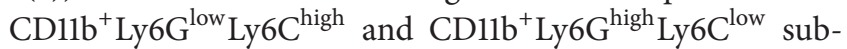
sets, respectively. Consistent with the results shown in Figures $1(\mathrm{~d})$ and $1(\mathrm{e})$, more than $99 \%$ of Ly6 $\mathrm{G}^{\text {high }} \mathrm{Ly} 6 \mathrm{C}^{\text {low }}$ myeloid cells in CLP $7 \mathrm{~d}$ mice were $\mathrm{CD}_{11 \mathrm{~b}}{ }^{+} \mathrm{CD} 48^{-}$, while $\mathrm{CD}_{11 b^{+}}$Ly6G $^{\text {low }}$ Ly6C $^{\text {high }}$ monocytic MDSC contained both 

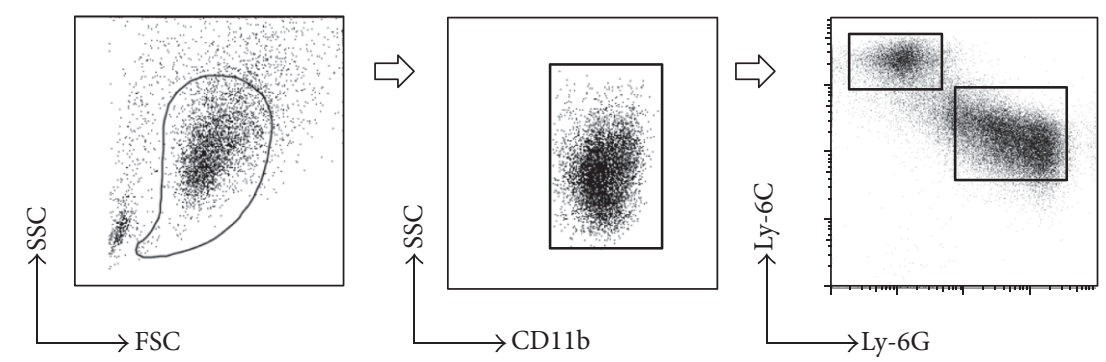

(a)
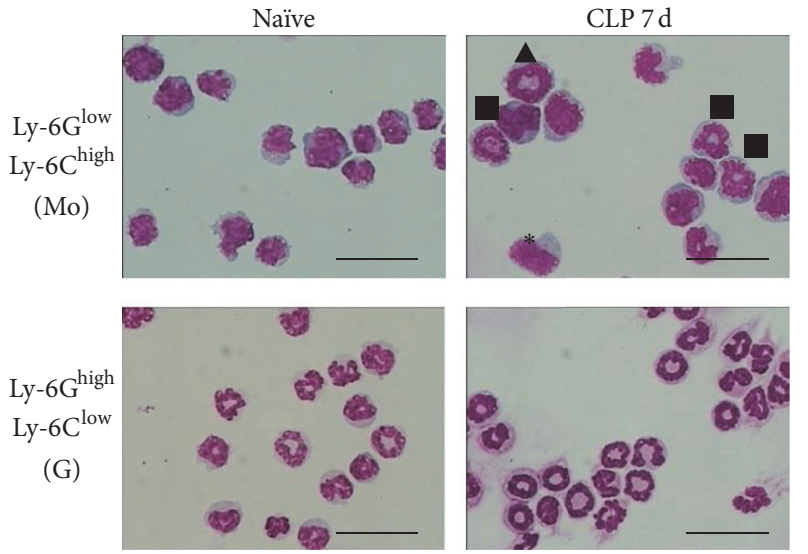

(b)

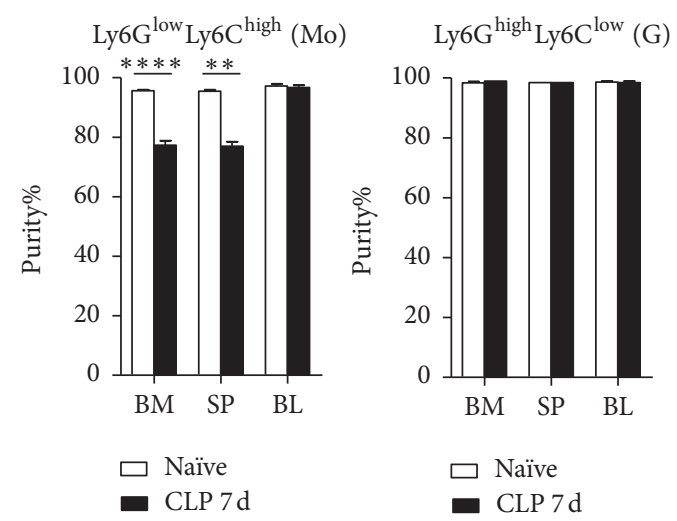

(c)
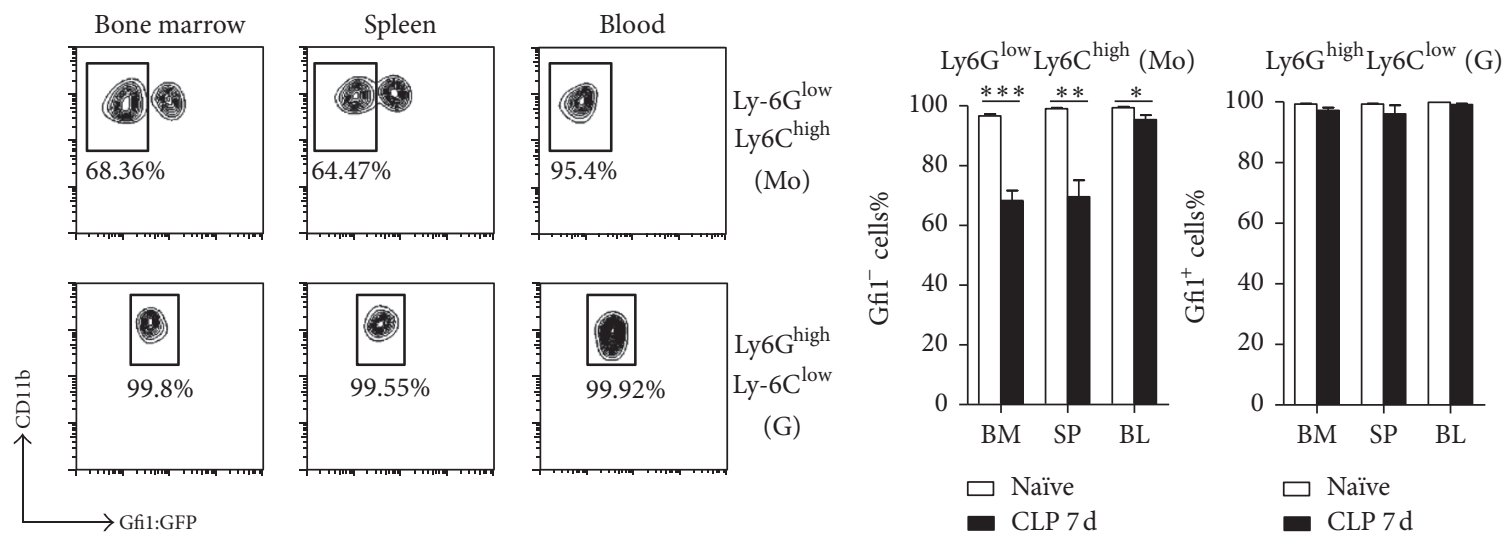

(d)

(e)

Figure 1: Purity of granulocytic and monocytic subpopulations identified by Ly6G and Ly6C. (a) Gating of monocytic and granulocytic MDSCs by Ly6C and Ly6G expression level. Cells were obtained from bone marrow, spleen, and blood from naïve and 7-day CLP Gfil:GFP knock-in mice. MDSCs were gated out from CD11b ${ }^{+}$cells and sorted as Ly6 $\mathrm{G}^{\text {high }}$ Ly6C ${ }^{\text {low }}$ granulocytes and Ly6G ${ }^{\text {low }}$ Ly6 $\mathrm{C}^{\text {high }}$ monocytes. $(\mathrm{b})$ Representative photomicrographs (images of bone marrow are shown) of Wright-Giemsa stained MDSC subsets; 200 cells were counted in each cell preparation. Bar $=10 \mu \mathrm{m},{ }^{*}$ monocyte, "segmented granulocyte, ${ }^{\mathbf{\Delta}}$ ring granulocyte. (c) Analysis of MDSC subset purity by cell morphology. (d) Gfil:GFP fluorescence of each MDSC subset was read. Representative graphs of flow cytometry analysis are shown. (e) Purity analysis of MDSC subsets by FACS. Data are mean \pm SEM of 5-8 mice per group, ${ }^{*} P<0.05,{ }^{* *} P<0.01,{ }^{* * *} P<0.001,{ }^{* * * *} P<0.0001$.

$\mathrm{CD} 11 \mathrm{~b}^{+} \mathrm{CD} 48^{+}$and $\mathrm{CD} 11 \mathrm{~b}^{+} \mathrm{CD} 48^{-}$populations (supplementary Figure 1 in Supplementary Material available online at https://doi.org/10.1155/2017/7521701).

We harvested bone marrow, spleen, and peripheral blood cells from Gfil:GFP knock-in mice at $3 \mathrm{~h}, 1$ day, 7 days, and 12 days after CLP for FACS analysis. The populations of $\mathrm{CD} 1 \mathrm{~b}^{+} \mathrm{CD} 48^{+}$cells were consistently $\mathrm{GFP}^{-/ \text {low }}$ at each of the test intervals, whereas the $\mathrm{CD}_{11 b^{+}} \mathrm{CD} 48^{-}$populations were consistently $\mathrm{GFP}^{+}$(Figures $3(\mathrm{f})$ and $3(\mathrm{~g})$ ). The same dynamic pattern was observed in the peripheral blood and spleens of septic mice. Thus, CD48 can distinguish granulocytes from monocytes in septic mice.

3.3. MDSC Purified by CD48-Based Cell Sorting Possessed Immune Suppressive Activity. We further tested the immune suppressive abilities of monocyte and granulocyte subsets 


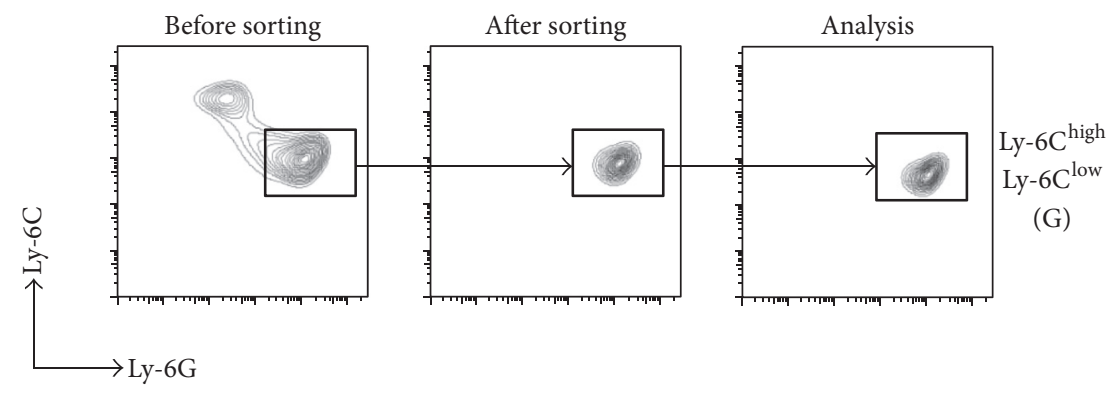

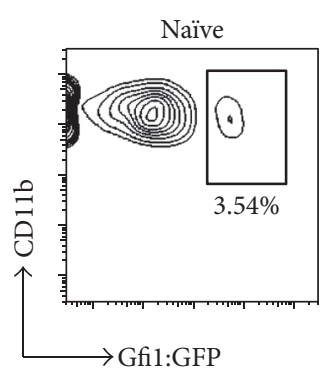

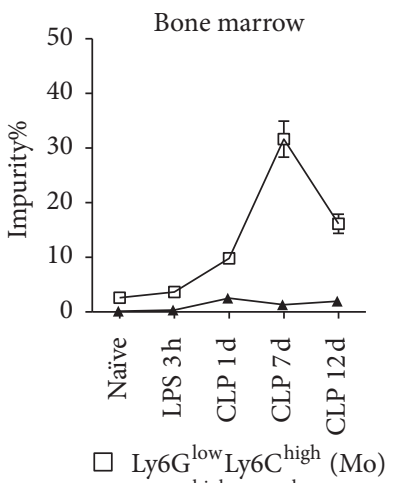

LPS $3 \mathrm{~h}$

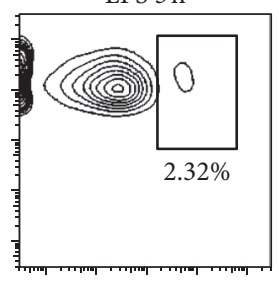

A Ly6G $^{\text {high }}$ Ly6C $^{\text {low }}(\mathrm{G})$ (a)
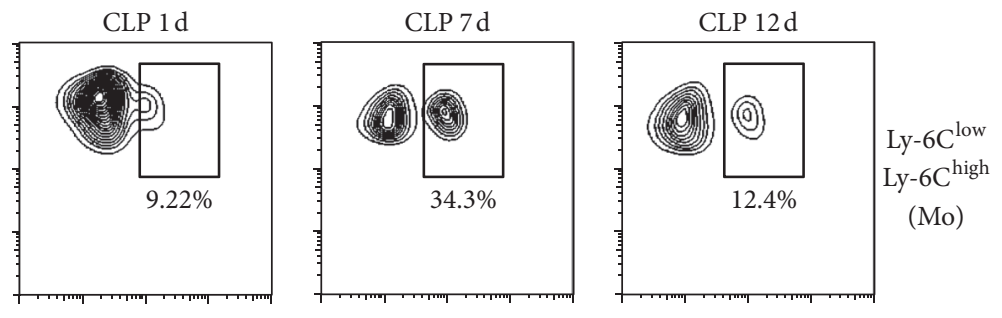

(b)
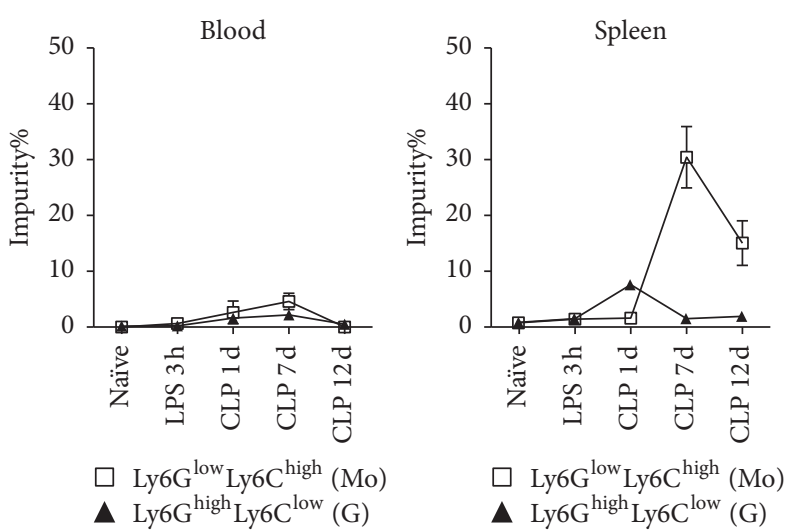

(c)

FIGURE 2: Influence of inflammation on Ly6C and Ly6G expression in MDSC subsets. (a) Sorted CD11b ${ }^{+}$Ly6G ${ }^{\text {high }}$ Ly6C ${ }^{\text {low }}$ G-MDSCs from the bone marrow of wild-type mice were cultured with LPS $(100 \mathrm{ng} / \mathrm{ml})$ in vitro for $3 \mathrm{~h}$, collected, and assayed by FACS. Representative graphs of flow cytometry analysis are shown. (b) Gfil:GFP knock-in mice were exposed to LPS (i.p. $10 \mathrm{mg} / \mathrm{kg}$ ) or CLP surgery. Bone marrow, spleen, and blood cells were stained with fluorescence-conjugated antibodies after $3 \mathrm{~h}$ LPS and on days 1, 7, and 12 after CLP. M-MDSCs were gated as CD11b ${ }^{+}$Ly6G ${ }^{\text {low }}$ Ly6C $C^{\text {high }}$ and their purity was evaluated by Gfil:GFP expression (graphs of bone marrow are shown). (c) Statistical analysis of flow cytometry data. Data are mean \pm SEM of 5-8 mice per group.

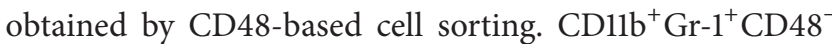

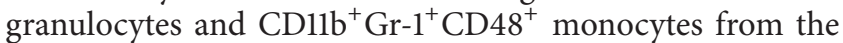
bone marrow and spleen of mice on day 7 after CLP were cocultured with splenic $\mathrm{CD} 4^{+} \mathrm{T}$ cells from naïve mice. As shown in Figure 4(a), the percentage of proliferating splenic $\mathrm{CD}^{+} \mathrm{T}$ cells decreased significantly along with an increase in MDSC/T ratio. We assayed the mRNA expression of two enzymes, Arg-1 and NOS2, which regulated MDSC-mediated immune suppression in granulocytes and monocytes defined by CD48 analyzing strategy. Both G-MDSCs and M-MDSCs from the septic bone marrow and the spleens exhibited increased NOS2 mRNA levels. However, we observed a discrepancy of Arg-1 expression between bone marrow and splenic MDSCs. Bone marrow G-MDSCs and M-MDSCs showed decreased levels of Arg-1 mRNA, while splenic GMDSCs and M-MDSCs displayed increased Arg-1 expression in septic mice (Figure 4(b))

\section{Discussion}

Along with the development of sepsis, MDSC populations in the bone marrow, spleen, and blood expand and modulate host immune responses [27, 28]. MDSCs appear to be divided into monocytic and granulocytic subpopulations with distinct functions $[8,29]$. Thus, the identification of specific MDSC subsets is prerequisite to a comprehensive understanding of their function. In malignancies and pathologies, the Ly6G and Ly6C cell surface markers can be used to 

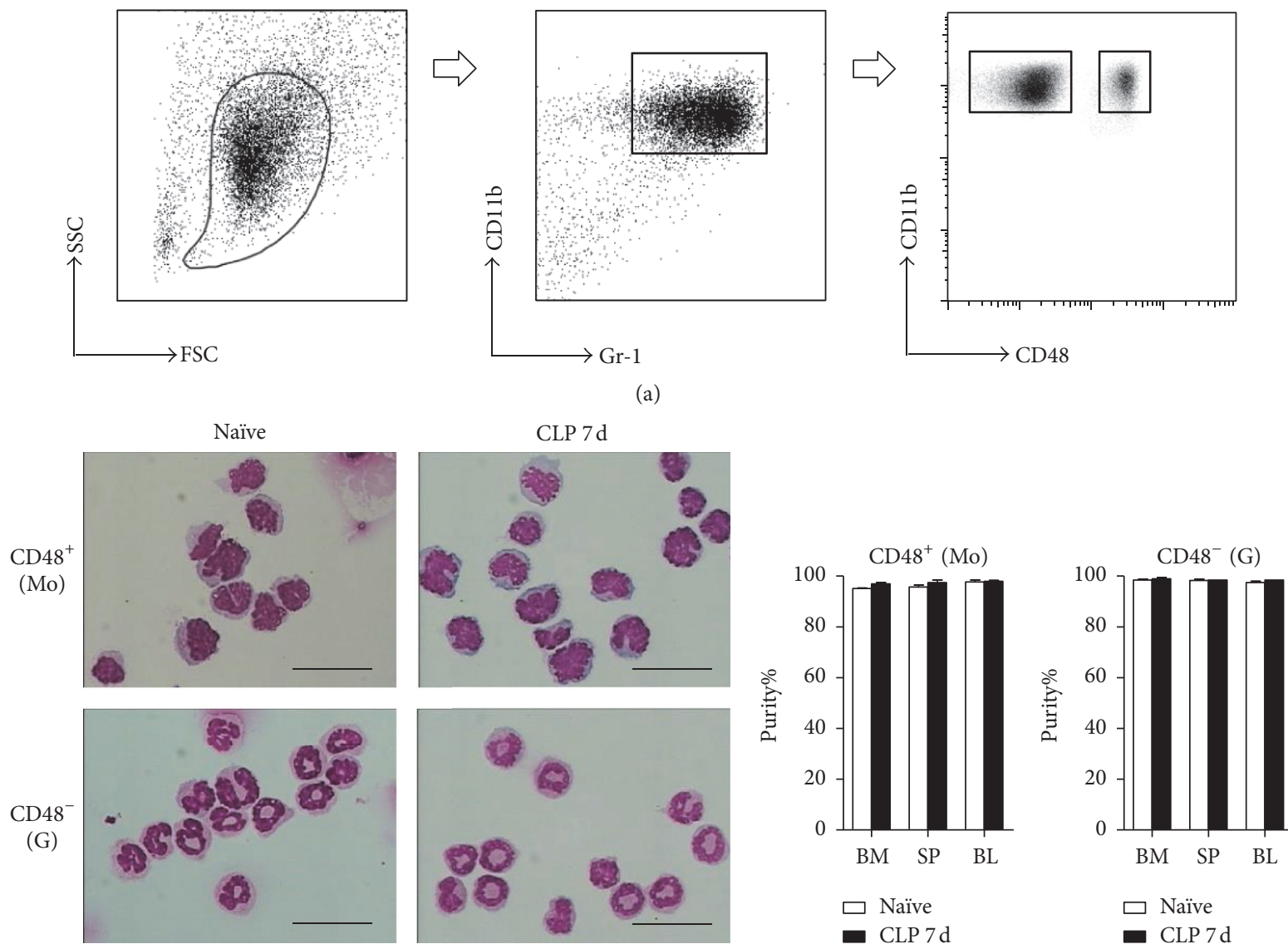

(b)

(c)
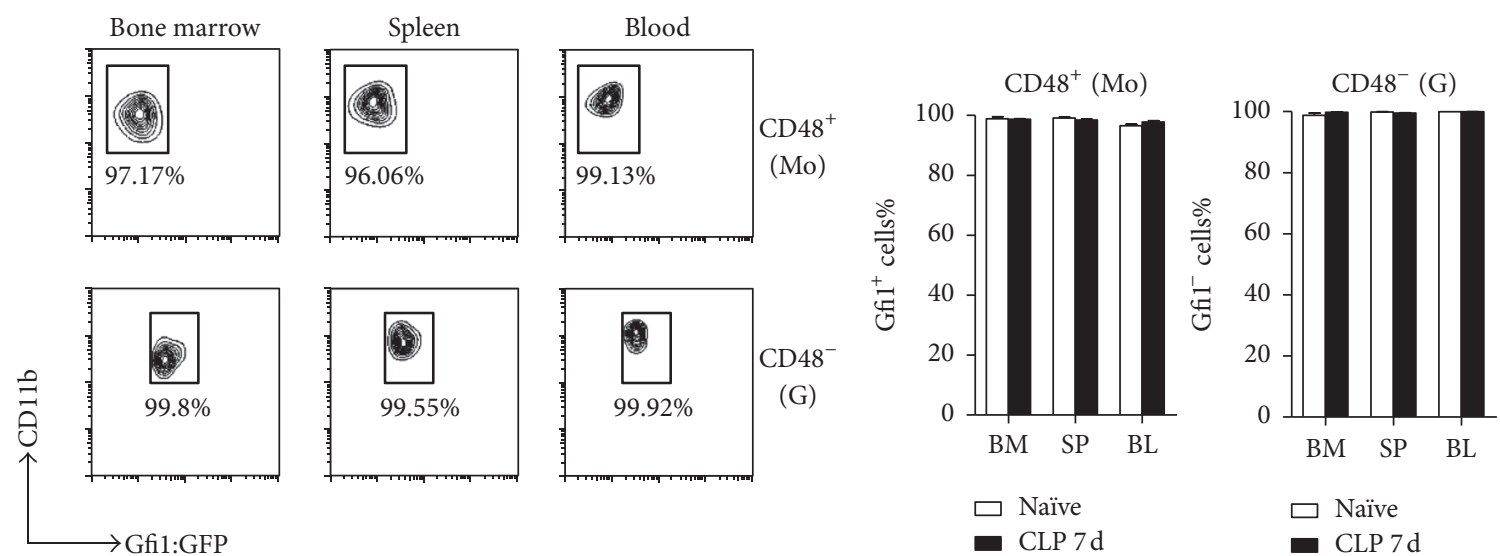

(d)
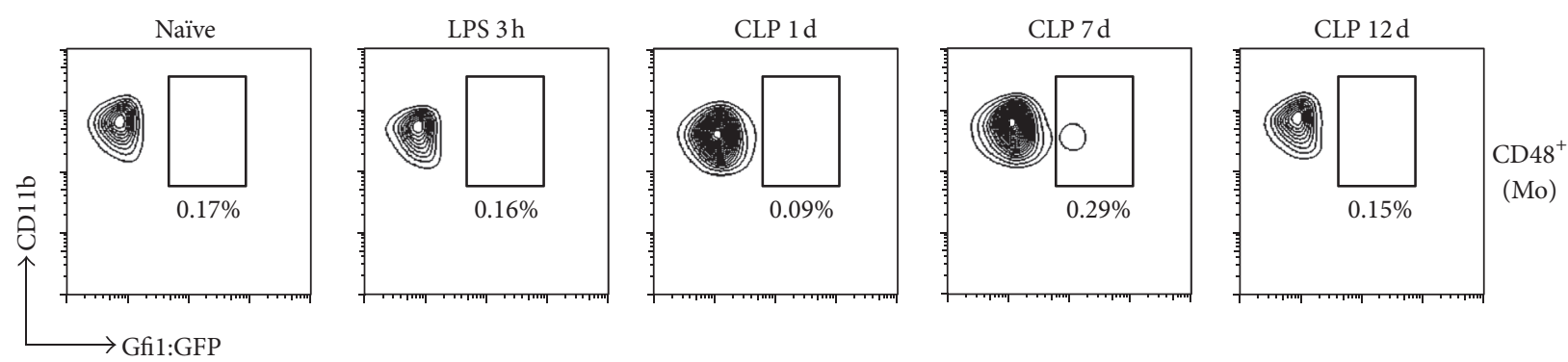

(f)

Figure 3: Continued. 

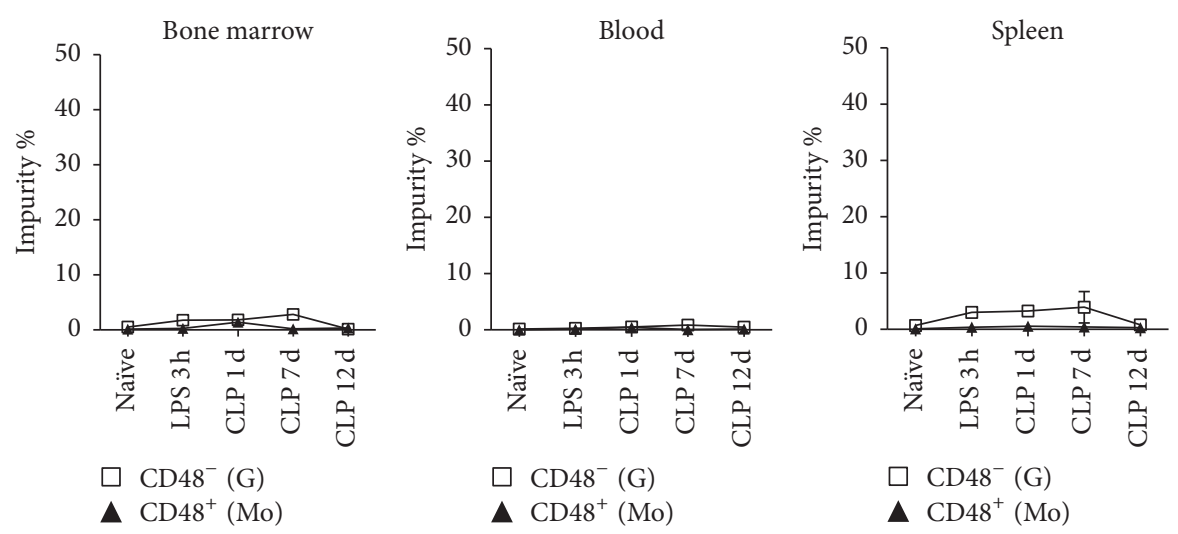

(g)

Figure 3: Granulocytic and monocytic MDSC subsets identified by CD48 expression. (a) Bone marrow, spleen, and blood cells were collected from naïve and 7-day CLP Gfil:GFP knock-in mice. MDSCs were gated as CD11b ${ }^{+}$Gr- $1^{+}$and sorted by CD48 expression. G-MDSCs

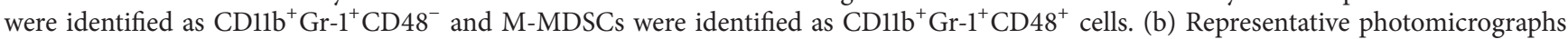
(images of bone marrow are shown) of Wright-Giemsa stained MDSC subsets, Bar $=10 \mu \mathrm{m}$. (c) Purity analysis of each MDSC subset by cell

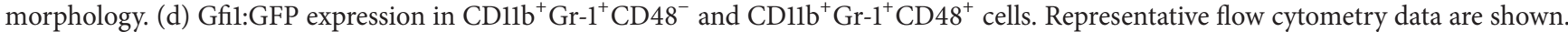
(e) Purity analysis of MDSC subsets by Gfil expression. (f) Gfil:GFP knock-in mice were treated with LPS (i.p. $10 \mathrm{mg} / \mathrm{kg}$ ) or by CLP surgery. Bone marrow, splenic, and blood cells from $3 \mathrm{~h}$ LPS treatment and days 1, 7, and 12 CLP surgery were assayed. The purity of CD11b ${ }^{+}$Gr$1^{+} \mathrm{CD} 48^{-}$M-MDSCs was evaluated by Gfil expression. Representative graphs of bone marrow flow cytometry assay are shown. (g) Statistical analysis of flow cytometry data. Data are mean \pm SEM of 5-8 mice per group.

distinguish $\mathrm{CD}_{11 b^{+}}$Ly6G $^{\text {low }}$ Ly6C ${ }^{\text {high }}$ monocytic MDSCs and $\mathrm{CD}_{11 b^{+}}$Ly6G $^{\text {high }}{ }^{\mathrm{Ly}} 6 \mathrm{C}^{\text {low }}$ granulocytic MDSCs [7, 30]. However, we found that, in sepsis, the Ly6G ${ }^{\text {low }}$ Ly6 $\mathrm{C}^{\text {high }}$ cell population included both monocytes and granulocytes, which indicated a variation of Ly6C and Ly6G expression in these myeloid cells under the inflammatory conditions of sepsis, and suggested that Ly6G/Ly6C expression may not be reliable for characterizing inflammation-induced MDSCs. Of note, similar phenomenon was also found in chronic inflammation [11]. Based on our previous report on transcription factor Gfi1 and cell surface marker CD48 in murine myeloid hematopoiesis [23], we evaluated CD48 as a marker to effectively distinguish granulocytic MDSCs from monocytic MDSCs in septic mice.

We found that some G-MDSCs and M-MDSCs share the $\mathrm{CD} 11 \mathrm{~b}^{+}$Ly6G ${ }^{\text {low }}$ Ly6C $\mathrm{C}^{\text {high }}$ phenotype, leading to a mixed population of granulocytes and monocytes, both with

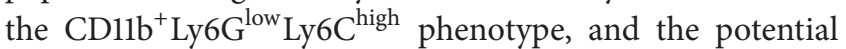
of inaccurately identifying monocytes. This inflammationrelated difference might be explained by the influence of inflammatory cytokines and mediators on the expression of myeloid cell surface markers [31]. That could explain the upregulation of Ly6C and downregulation of Ly6G molecules on the surface of granulocytes. However, the in vitro results of LPS stimulation imply that inflammation might not directly influence the expression of Ly6C and Ly6G by mature granulocytes. The significant increase in myelopoiesis in response to sepsis that we and others have identified occurs at the level of stem cells and primitive progenitors and may lead to dramatic changes in mature myeloid

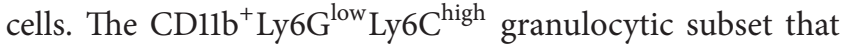
we observed may thus be a newly generated population arising during "emergency" hematopoiesis. The increase in

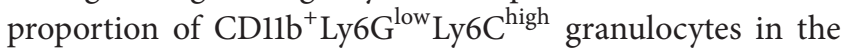
bone marrow and spleen accelerated with the progression of sepsis and with the progression of enhanced myelopoiesis. Thus, the emergency hematopoiesis during the development and aggravation of sepsis may contribute to the expansion of the novel granulocyte population.

Interestingly, we found that granulocytes with the Ly6G ${ }^{\text {low }}$ Ly6 $C^{\text {high }}$ phenotype primarily resided in the bone marrow and the spleen, and not in the peripheral blood. This granulocyte subset might represent a stage of differentiation in the bone marrow and spleen, or a population with a reduced capacity of emigration from the hematopoietic organs. Another explanation is that the phenotype changes following migration into the peripheral blood. These possibilities should be investigated in future studies.

In contrast to dramatically decreased levels of Arg-1 in both G-MDSCs and M-MDSCs in the bone marrow, splenic G-MDSCs and M-MDSCs exhibited increased Arg-1 expression at day 7 after CLP surgery. Since inflammationinduced MDSCs arise from "emergency" hematopoiesis, such discrepancy of Arg-1 expression levels between bone marrow and splenic MDSCs might be a result from different inflammatory microenvironments for MDSC development during intramedullary hematopoiesis (the bone marrow) and extramedullary hematopoiesis (the spleen).

\section{Conclusion}

In summary, our findings present a novel characterization of myeloid cells during inflammation. In inflammatory conditions, CD48 staining and FACS allowed more accurate 

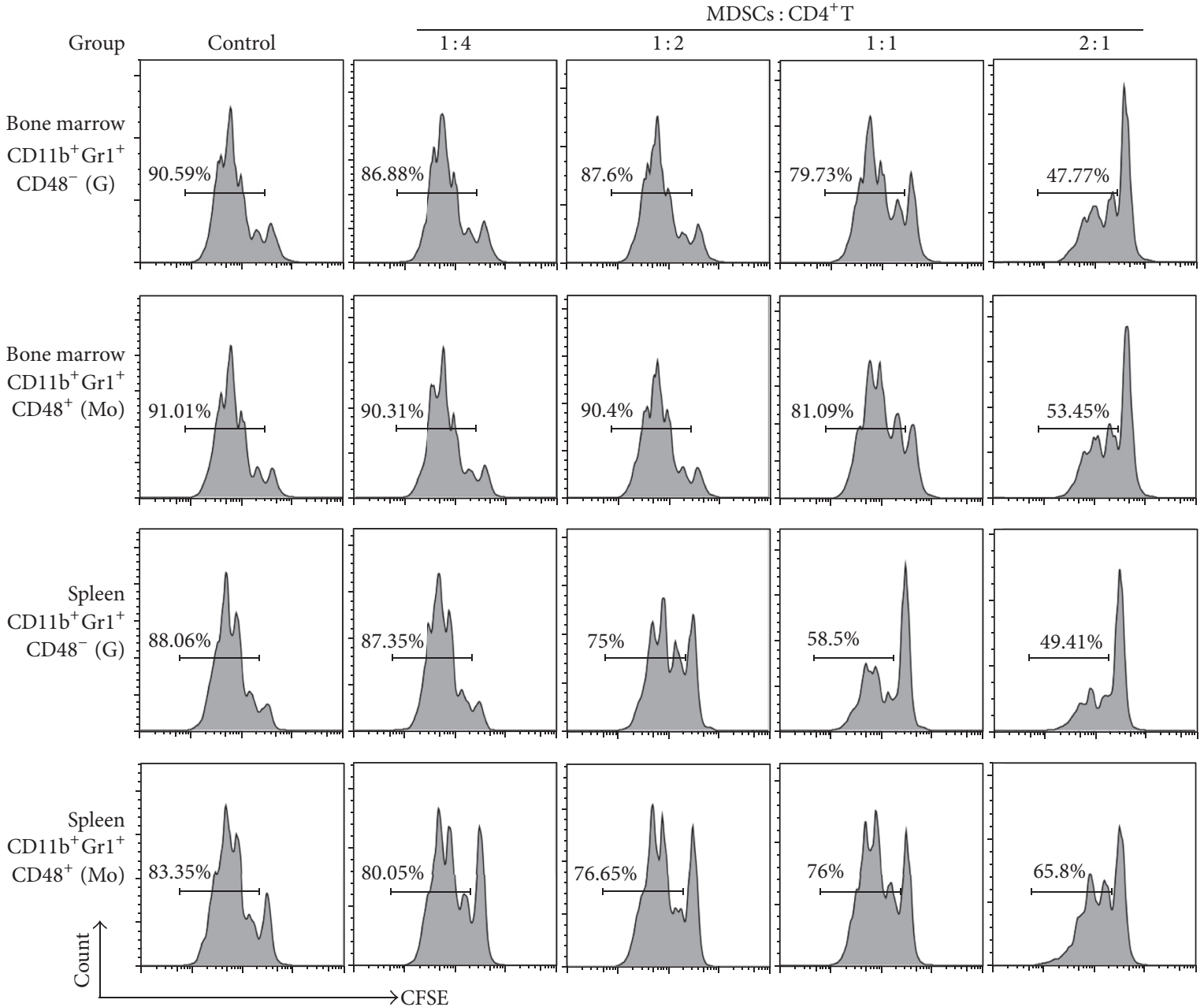

(a)
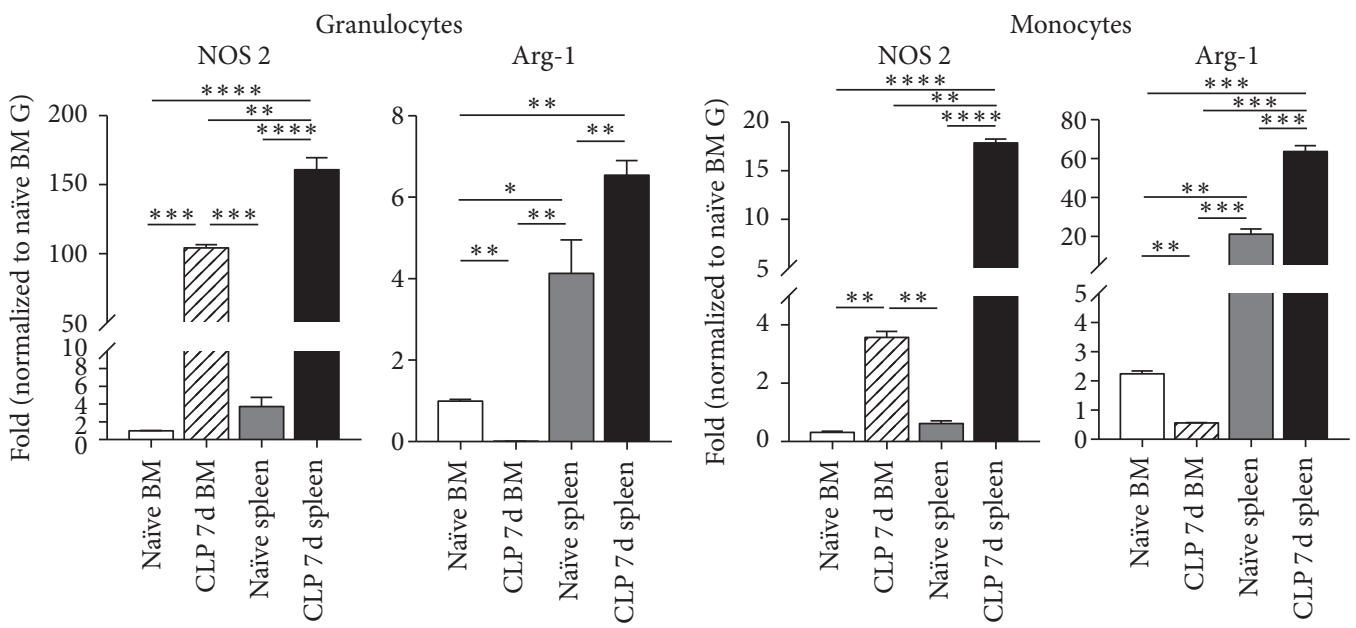

(b)

FIgURE 4: Immune suppression by MDSCs sorted by Gfil:GFP expression. (a) Sorted MDSC subsets were cocultured with CFSE-labeled splenic $\mathrm{CD} 4^{+} \mathrm{T}$ cells isolated from naïve spleen by magnetic cell sorting. Anti-CD3 and anti-CD28 antibodies were applied to induce CD4 ${ }^{+}$ $\mathrm{T}$-cell proliferation. After $72 \mathrm{~h}$, the proportion of proliferating CD $4^{+} \mathrm{T}$ cells was evaluated by CFSE staining and flow cytometry. Representative graphs show data from three independent replications. (b) Sorted CD $11 \mathrm{~b}^{+} \mathrm{Gr}-\mathrm{1}^{+} \mathrm{CD} 48^{-} \mathrm{G}-\mathrm{MDSC}$ and CD $11 \mathrm{~b}^{+} \mathrm{Gr}-\mathrm{1}^{+} \mathrm{CD} 48^{+} \mathrm{M}-\mathrm{MDSC}$ were analyzed by real-time qPCR. Probes detecting NOS2 and Arg-1 were used to quantify mRNA levels. Relative expression was normalized to bone marrow derived granulocytes from naïve mice. Data are mean \pm SEM of 6-10 mice per group. The experiment was repeated three times, and the values presented are from one representative experiment. ${ }^{*} P<0.05,{ }^{* *} P<0.01,{ }^{* * *} P<0.001,{ }^{* * * *} P<0.0001$. 
identification of bone marrow and splenic granulocytes and monocytes than possible with Ly6G/Ly6C. Using this method, we investigated the immune suppressive function of monocytic and granulocytic MDSCs. Our findings assist in studying myeloid cell subsets and add to our understanding of their immune regulatory functions.

\section{Competing Interests}

The authors declare no conflict of interests regarding the publication of this paper.

\section{Acknowledgments}

This study was supported by grants from the Natural Science Foundation of Beijing Municipality (no. 7142080) and the National Natural Science Foundation of China (nos. 81200316,81573955 , and 30872458 ). The authors would like to thank Professor Tarik Möröy for his professional comments and kind gift of Gfil:GFP knock-in mice.

\section{References}

[1] D. I. Gabrilovich and S. Nagaraj, "Myeloid-derived suppressor cells as regulators of the immune system," Nature Reviews Immunology, vol. 9, no. 3, pp. 162-174, 2009.

[2] E. Peranzoni, S. Zilio, I. Marigo et al., "Myeloid-derived suppressor cell heterogeneity and subset definition," Current Opinion in Immunology, vol. 22, no. 2, pp. 238-244, 2010.

[3] J. E. Talmadge and D. I. Gabrilovich, "History of myeloidderived suppressor cells," Nature Reviews Cancer, vol. 13, no. 10, pp. 739-752, 2013.

[4] K. Hestdal, F. W. Ruscetti, J. N. Ihle et al., "Characterization and regulation of RB6-8C5 antigen expression on murine bone marrow cells," The Journal of Immunology, vol. 147, no. 1, pp. 2228, 1991.

[5] T. J. Fleming, M. L. Fleming, and T. R. Malek, "Selective expression of Ly-6G on myeloid lineage cells in mouse bone marrow. RB6-8C5 mAb to granulocyte-differentiation antigen (Gr-1) detects members of the Ly-6 family," The Journal of Immunology, vol. 151, no. 5, pp. 2399-2408, 1993.

[6] S. Rose, A. Misharin, and H. Perlman, "A novel Ly6C/Ly6Gbased strategy to analyze the mouse splenic myeloid compartment," Cytometry Part A, vol. 81, no. 4, pp. 343-350, 2012.

[7] J.-I. Youn and D. I. Gabrilovich, "The biology of myeloidderived suppressor cells: the blessing and the curse of morphological and functional heterogeneity," European Journal of Immunology, vol. 40, no. 11, pp. 2969-2975, 2010.

[8] A. Mantovani, "The growing diversity and spectrum of action of myeloid-derived suppressor cells," European Journal of Immunology, vol. 40, no. 12, pp. 3317-3320, 2010.

[9] S. Ostrand-Rosenberg and P. Sinha, "Myeloid-derived suppressor cells: linking inflammation and cancer," Journal of Immunology, vol. 182, no. 8, pp. 4499-4506, 2009.

[10] M. Derive, Y. Bouazza, C. Alauzet, and S. Gibot, "Myeloidderived suppressor cells control microbial sepsis," Intensive Care Medicine, vol. 38, no. 6, pp. 1040-1049, 2012.

[11] B. Höchst, J. Mikulec, T. Baccega et al., "Differential induction of Ly6G and Ly6C positive myeloid derived suppressor cells in chronic kidney and liver inflammation and fibrosis," PLoS ONE, vol. 10, no. 3, Article ID e0119662, 2015.

[12] L. Wang, W.-B. Yu, L.-Y. Tao, and Q. Xu, "Myeloid-derived suppressor cells mediate immune suppression in spinal cord injury," Journal of Neuroimmunology, vol. 290, pp. 96-102, 2016.

[13] P. Boros, J. Ochando, and M. Zeher, "Myeloid derived suppressor cells and autoimmunity," Human Immunology, vol. 77, no. 8, pp. 631-636, 2016.

[14] M. Ioannou, T. Alissafi, L. Boon, D. Boumpas, and P. Verginis, "In vivo ablation of plasmacytoid dendritic cells inhibits autoimmunity through expansion of myeloid-derived suppressor cells," Journal of Immunology, vol. 190, no. 6, pp. 2631-2640, 2013.

[15] Y. He, J. Bei, H. Zeng, and Z. Pan, "The roles of sepsis-induced myeloid derived suppressor cells in mice corneal, skin and combined transplantation," Transplant Immunology, vol. 34, pp. 8-13, 2016.

[16] P. Y. Lee, J.-X. Wang, E. Parisini, C. C. Dascher, and P. A. Nigrovic, "Ly6 family proteins in neutrophil biology," Journal of Leukocyte Biology, vol. 94, no. 4, pp. 585-594, 2013.

[17] D. B. Jutila, S. Kurk, and M. A. Jutila, "Differences in the expression of Ly-6C on neutrophils and monocytes following PI-PLC hydrolysis and cellular activation," Immunology Letters, vol. 41, no. 1, pp. 49-57, 1994.

[18] I. H. Hiemstra, K. Vrijland, M. M. Hogenboom, G. Bouma, G. Kraal, and J. M. M. den Haan, "Intestinal epithelial cell transported TLR2 ligand stimulates Ly6C+ monocyte differentiation in a G-CSF dependent manner," Immunobiology, vol. 220, no. 11, pp. 1255-1265, 2015.

[19] M. A. Fischer, M. L. Davies, I. E. Reider et al., "CD11b', Ly $6 \mathrm{G}^{+}$cells produce type I interferon and exhibit tissue protective properties following peripheral virus infection," PLoS Pathogens, vol. 7, no. 11, Article ID e1002374, 2011.

[20] T. Möröy and C. Khandanpour, "Growth factor independence 1 (Gfil) as a regulator of lymphocyte development and activation," Seminars in Immunology, vol. 23, no. 5, pp. 368-378, 2011.

[21] H. Hock, M. J. Hamblen, H. M. Rooke et al., "Gfi-1 restricts proliferation and preserves functional integrity of haematopoietic stem cells," Nature, vol. 431, no. 7011, pp. 1002-1007, 2004.

[22] H. Zeng, R. Yücel, C. Kosan, L. Klein-Hitpass, and T. Möröy, "Transcription factor Gfil regulates self-renewal and engraftment of hematopoietic stem cells," EMBO Journal, vol. 23, no. 20, pp. 4116-4125, 2004.

[23] L. Vassen, U. Duhrsen, C. Kosan et al., "Growth factor independence 1 (Gfil) regulates cell-fate decision of a bipotential granulocytic-monocytic precursor defined by expression of Gfil and CD48," American Journal of Blood Research, vol. 2, pp. 228 242, 2012.

[24] H. Karsunky, H. Zeng, T. Schmidt et al., "Inflammatory reactions and severe neutropenia in mice lacking the transcriptional repressor GFil," Nature Genetics, vol. 30, pp. 295-300, 2002.

[25] H. Hock, M. J. Hamblen, H. M. Rooke et al., "Intrinsic requirement for zinc finger transcription factor Gfi-1 in neutrophil differentiation," Immunity, vol. 18, no. 1, pp. 109-120, 2003.

[26] R. Yücel, C. Kosan, F. Heyd, and T. Möröy, "Gfil:green fluorescent protein knock-in mutant reveals differential expression and autoregulation of the growth factor independence 1 (Gfil) gene during lymphocyte development," Journal of Biological Chemistry, vol. 279, no. 39, pp. 40906-40917, 2004.

[27] V. Bronte, "Myeloid-derived suppressor cells in inflammation: uncovering cell subsets with enhanced immunosuppressive 
functions," European Journal of Immunology, vol. 39, no. 10, pp. 2670-2672, 2009.

[28] L. Brudecki, D. A. Ferguson, C. E. McCall, and M. E. Gazzar, "Myeloid-derived suppressor cells evolve during sepsis and can enhance or attenuate the systemic inflammatory response," Infection and Immunity, vol. 80, no. 6, pp. 2026-2034, 2012.

[29] E. Ribechini, V. Greifenberg, S. Sandwick, and M. B. Lutz, "Subsets, expansion and activation of myeloid-derived suppressor cells," Medical Microbiology and Immunology, vol. 199, no. 3, pp. 273-281, 2010.

[30] J.-I. Youn, S. Nagaraj, M. Collazo, and D. I. Gabrilovich, "Subsets of myeloid-derived suppressor cells in tumor-bearing mice," Journal of Immunology, vol. 181, no. 8, pp. 5791-5802, 2008.

[31] T. Condamine and D. I. Gabrilovich, "Molecular mechanisms regulating myeloid-derived suppressor cell differentiation and function," Trends in Immunology, vol. 32, no. 1, pp. 19-25, 2011. 


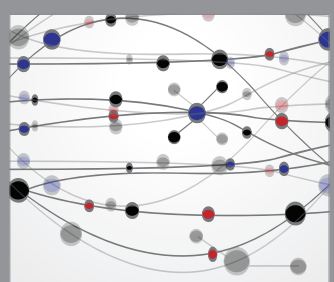

The Scientific World Journal
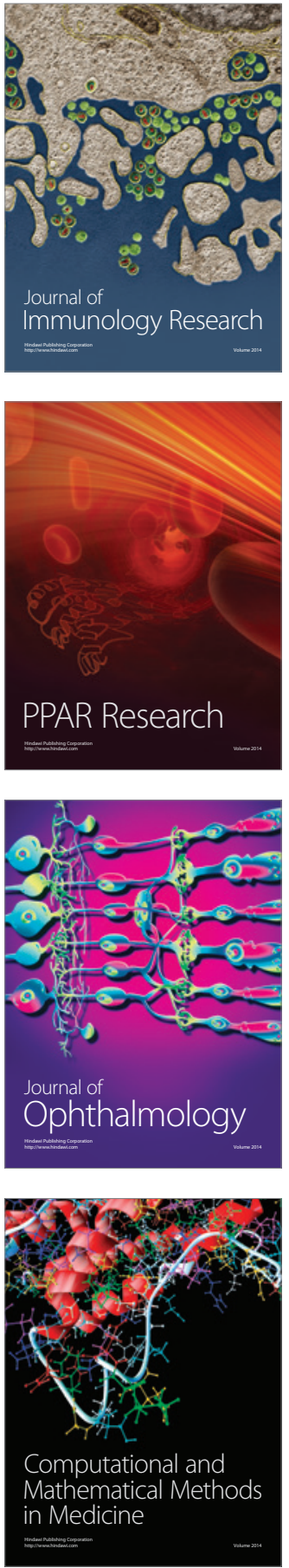

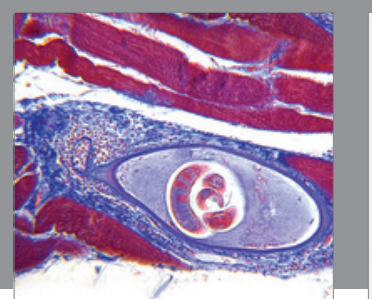

Gastroenterology Research and Practice
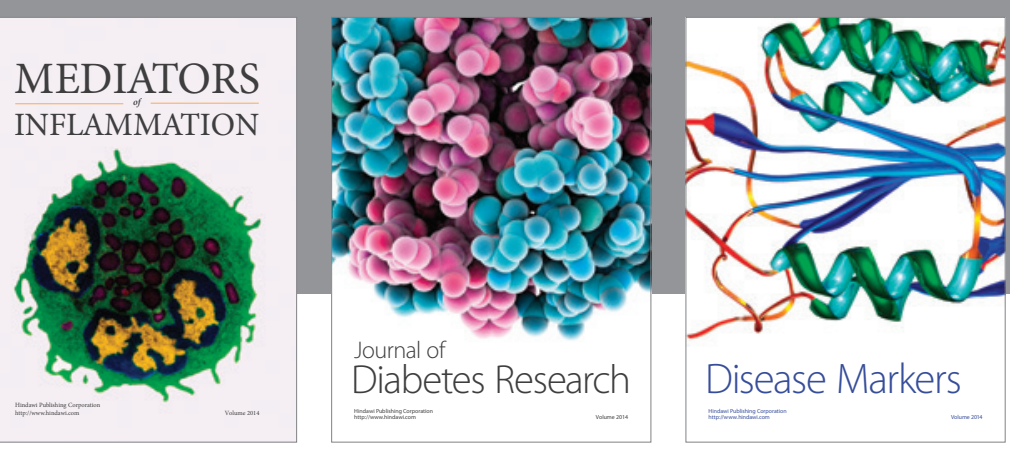

Disease Markers

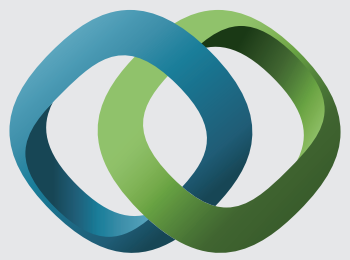

\section{Hindawi}

Submit your manuscripts at

https://www.hindawi.com
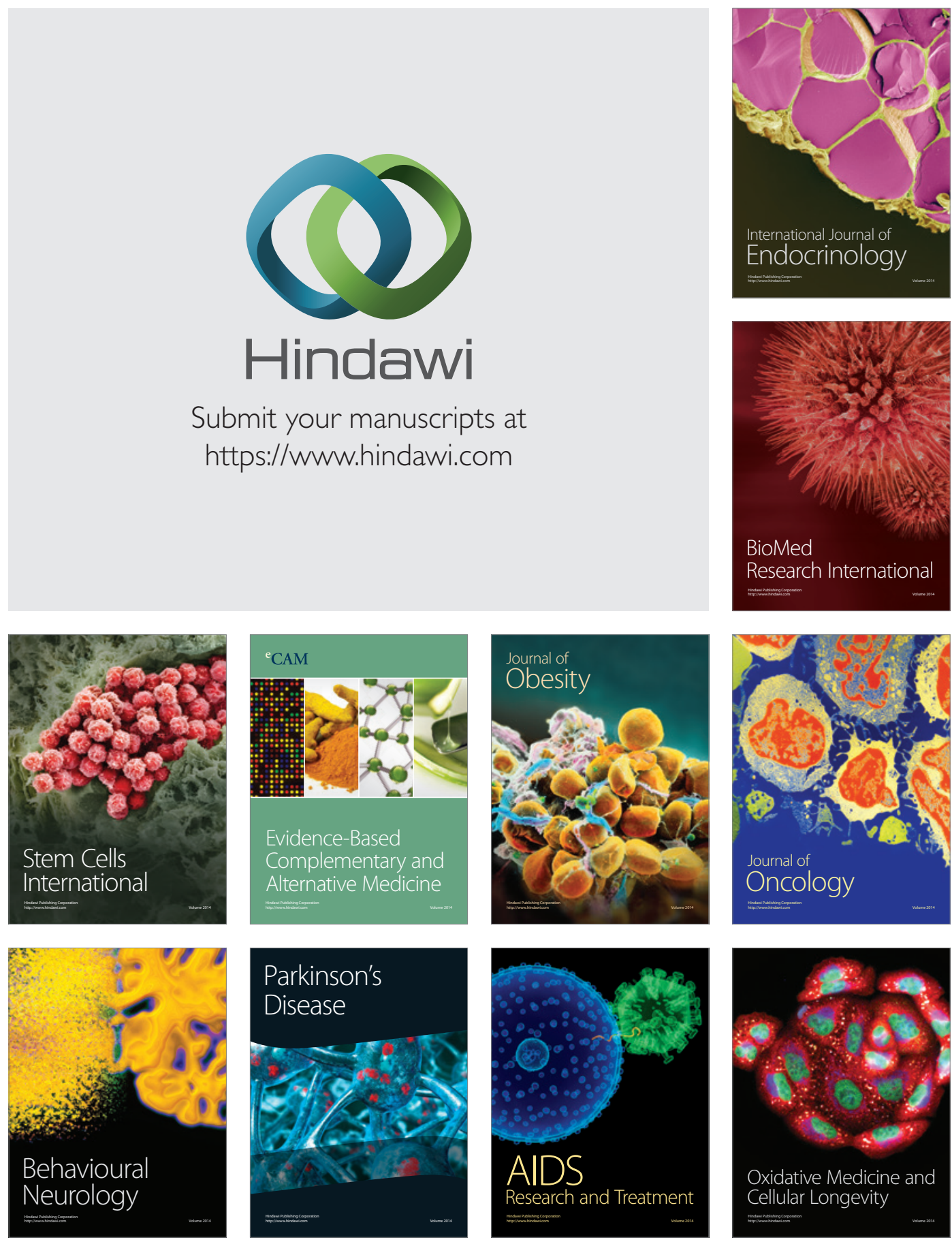